\title{
Levantamento do Meio BioFísico e Avaliação da Fragilidade do Ecossistema na Estação Ecológica dos Caetetus - SP.
}

\author{
Isabel F.A. Mattos'; Marcio Rossi²; Dimas A. Silva'; Rui M.Pfeifer ${ }^{2}$ \\ 'IF - Instituto Florestal - CP 1322 CEP 01051-970- São Paulo - SP \\ 'IAC - Instituto Agronômico - CP 28 CEP 13001-970 - Campinas - SP
}

\begin{abstract}
The study aim to survey the biophisical and fragility characteristics of environment at "Estação Ecológica dos Caetetus" of São Paulo State - Brazil, through the photointerpretation and field works. The fragility class was obtained with the relations among soil, geomorphology and vegetation cover characteristics. It was concluded that area is all fragile decurrent of slope, deep, drainage of soil and vegetation cover alteration. Many problems occur thoroughly Ecological Station due the inadequated use and erosion process nearly Station's area.
\end{abstract}

Keywords: Biophisical survey; fragility;

Introdução

A Estação Ecológica dos Caetetus é uma das poucas áreas do oeste do Estado de São Paulo coberta pela Floresta Mesófila semidecidua, uma das últimas remanescentes do interior, que além de abrigar a flora, preserva espécies da fauna ameaçadas de extinção, como o "mico leão preto" (Leontopithecus chrysopigus). Para tanto, este trabalho objetiva apresentar $o$ levantamento do meio bio-físico e identificar setores de diferentes graus de fragilidade, de modo a subsidiar o plano de manejo, atualmente em elaboração pelo Instituto Florestal.

\section{Material e Métodos}

A Estação Ecológica dos Caetetus, com área de $2.178,84$ ha, localiza-se nos municipios de Gália e Alvinlândia, entre as coordenadas geográficas $22^{\circ} 46^{\prime} \mathrm{e}$ $22^{\circ} 41^{\prime}$ de latitude sul e $49^{\circ} 16^{\prime}$ e $49^{\circ} 10^{\prime}$ de longitude oeste Gr. (FIGURA 1).

Encontra-se no Planalto Ocidental sobre arenitos da Formação Marilia e Adamantina com cimento calcáreo, predominando os latossolos de textura média nos topos e os podzólicos abruptos nas vertentes. $O$ clima segundo Köppen é Cwa, mesotérmico de inverno seco.

Para o mapeamento do meio biofísico utilizou-se fotos aéreas na escala aproximada de 1:35.000, ano de 1984 e mapas topográficos do IBGE na escala 1:50.000, ano de 1973.

Através da fotointerpretação e trabalhos de campo obteve-se mapas da rede de drenagem, geomorfológico, solos e vegetação. Para subsidiar a avaliação da fragilidade do ecossistema confeccionou-se mapas hipsométrico, declividade e perfis topográficos.

Para o estabelecimento das relações entre os elementos do meio bio-físico e a obtenção dos diferentes graus de fragilidade adaptou-se a metodologia de ROSS (1991) e MATTOS (1994).

À partir da caracterização do meio bio-físico e das limitaçôes impostas por seus atributos (compartimentação do relevo, morfodinâmica, declive, litologia, profundidade e textura dos solos, e estrutura da vegetação), definiram-se setores da área com diferentes graus de fragilidade.

A vegetação foi avaliada não só como fator de proteção dos solos, mas também, foi considerado o seu nivel de degradação e consequente capacidade de fornecer abrigo e alimentação à fauna.

Desta forma, através da avaliação qualitativa do meio identificou-se quatro classes de fragilidade (pouco frágil, frágil, muito frágil e extremamente frágil), que visam a sua diagnose, proporcionando indícios para a conservação do solo e manutenção do equilibrio da fauna e flora da Estação Ecológica dos Caetetus.

\section{Resultados e Discussão}

São apresentados no Quadro 1 as diferentes classes de fragilidade do ecossistema, destacadas e espacializadas na Figura 2, assim descritas:

I - O relevo plano com solos profundos e boa drenagem interna, confere a este setor baixa fragilidade, todavia, a característica da vegetação atual, o transforma em um ambiente frágil, pois esta, encontrase bastante degradada pela ação antrópica (efeito 
borda), provocando perdas em sua composição e estrutura

II - Este setor apresenta as mesmas caraceristicas do meio físico que o anterior. A vegetação por sua vez, apresenta composição e estrutura originais, nota-se porém, a presença de espécies invasoras e um efeito borda menos intenso. Estas características conjugadas, conferem a este setor uma classe pouco fragil.

III - Quanto ao meio físico, apesar de apresentar longas vertentes com declives baixos, as limitações aparecem em função da relação textural abrupta do solo, conferindo uma baixa condutividade hidráulica, 0 que propicia circulação lateral da água e consequente aparecimento de erosão. Este setor é portanto, frágil, apesar da vegetação apresentar pequeno grau de interferência antrópica nesta área.

IV - Este setor é extremamente frágil, pois além de apresentar as mesmas limitações impostas pelo solo do item anterior, a cobertura vegetal encontra-se muito impactada, diminuindo assim, a proteção dos solos e a oferta de abrigo e alimento à fauna.

V - Os declives acentuados, em solos de pouca profundidade, acentua a circulação lateral e superficial de água, o que propicia maior tendência à processos erosivos, tornando o setor frágil, apesar de apresentar vegetação protetora (arbóreo alto)

VI - Quanto ao meio físico, apresenta-se como no setor V (fragil), que associada a vegetação bastante impactada (arbóreo baixo denso), torna a área extremamente frágil.

VII - Apresenta relevo escarpado com declives acentuados ( $>45 \%$ ) e solos com pequena profundidade, o que propicia uma circulação de água superficial intensa, acentuando a remoção de material (erosão), podendo ocorrer movimentos de massa naturais e/ou induzidos e queda de blocos. Porém, a presença da cobertura vegetal arbórea protege este setor, que é fragil significando que qualquer interferência nesta cobertura poderá causar a intensificação da fragilidade da área.

VIII - Este setor é frágil, pois apresenta relevo de colinas amplas com baixas declividades, porém em solos com relação textural alta e condutividade hidráulica descontínua, 0 que propicia 0 desenvolvimento de processos erosivos e a vegetação arbórea alta, confere a este setor, uma maior proteção, minimizando a fragilidade ocasionada pelo aspecto físico.

IX - Apresenta-se com as mesmas características do meio fisico do ítem anterior, porém a vegetação por ser arbórea baixa a média, confere uma menor proteção aos solos e a fauna, tornando a área muito frágil.

$\mathbf{X}$ - Quanto ao meio físico, apresenta-se como no setor VIII, porém sua cobertura vegetal é muito impactada (arbóreo baixo denso), o que torna o setor extremamente frágil devido à perda de espécies vegetais, interferindo de forma negativa no equilíbrio da fauna existente.

XI - É representado pelas restritas planícies aluviais que ocorrem na área, caracterizadas por relevo plano com pouca profundidade efetiva do solo, resultado do elevado nivel do lençol freático. É ainda, uma zona de deposição de materiais, sujeita a inundações periódicas. Frágeis em relação ao manejo, apresentam uma vegetação típica (herbácea e arbóreo baixo) que lhe confere caráter protetor, tornando a área frágil; deve-se lembrar que esta zona, é passagem obrigatória da fauna, que a utiliza, principalmente, para obtenção de água, e que portanto, deve ter um mínimo de interferência antrópica.

XII - Este setor apresenta depósitos de detrítos instáveis (tálus e rampas de colúvio). Ocorrem, normalmente, desde os sopés até as partes médias das vertentes. Os solos apresentam as mesmas carcterísticas descritas no ítem III, portanto muito suscetíveis à erosão que as tornam mais fragilizadas. Todavia, a vegetação do tipo arbóreo alto, confere uma maior proteção, tornando a área frágil.

\section{Conclusões}

De maneira geral, nos três compartimentos estudados, planalto, escarpa e colinas, o ecossistema se revelou frágil do ponto de vista do meio bio-físico, tendo como principais fatores limitantes, a declividade, a profundidade e drenagem interna do solo e a alteração da cobertura vegetal.

Observa-se que muitos dos problemas detectados na Estação Ecológica, são reflexos do mal uso do seu entorno. Assim, os processos erosivos que ocorrem fora da Unidade de Conservação, influenciam diretamente no assoreamento dos cursos d'água (sedimentação, perda da qualidade e quantidade de água), comprometendo sua utilização tanto pela fauna como no desenvolvimento normal das espécies vegetais.

Verifica-se ainda, que as perturbações ocorridas, em passado recente, na área de mata que envolve a Estação, são sentidas pela diminuição de espécies nativas e invasão de essências exóticas, agravadas pela ocorrência da passagem de fogo nos pastos vizinhos, do maior impacto do vento e presença de caçadores, coletores e outros, aumentando o efeito borda e diminuindo a frequência da fauna.

Para que o ecossistema se equilibre, fáz-se necessário medidas de preservação e conservação do solo do entorno da Estação Ecológica, recuperando as nascentes dos cursos d'água, principalmente no que concerne às cabeceiras da bacia hidrográfica da Estação Ecológica dos Caetetus. 


\section{Referências bibliográficas}

ROSS, J. L.S. 1990 Geomorfologia: ambiente e planejamento. São Paulo: Contexto (Coleção repensando a geografia. $83 \mathrm{p}$.

MATTOS, I. F.A. 1994 A fisionomia vegetal e suas relaçôes com o meio físico na definição das unidades de paisagem na alta bacia do rio Turvo-SP. São Paulo ( Dissertação de Mestrado) Dep. de Geogr. da FFLCH -USP. $141 \mathrm{P}$. 


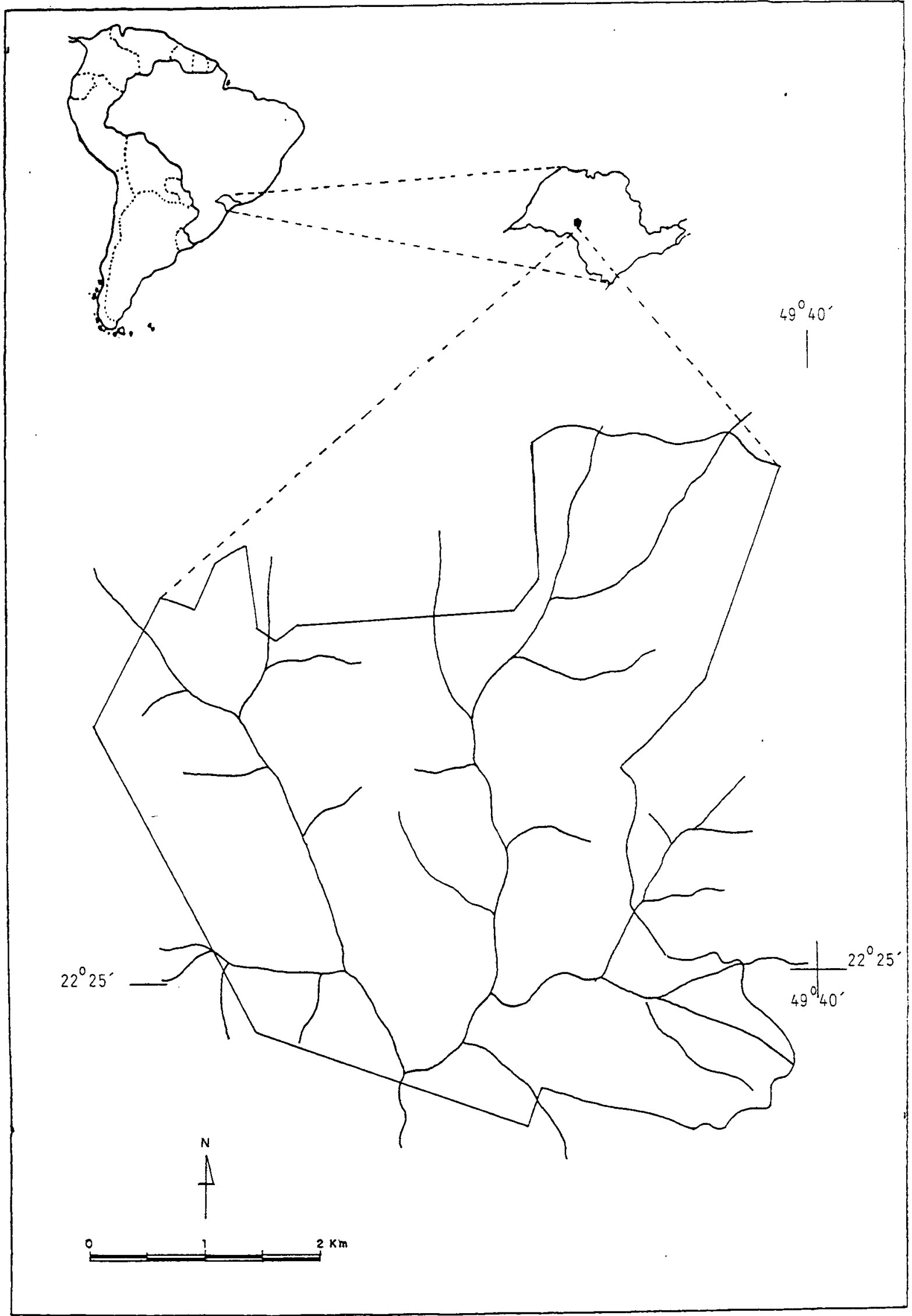

Figura 1 : Localizaça da área de estudos. 


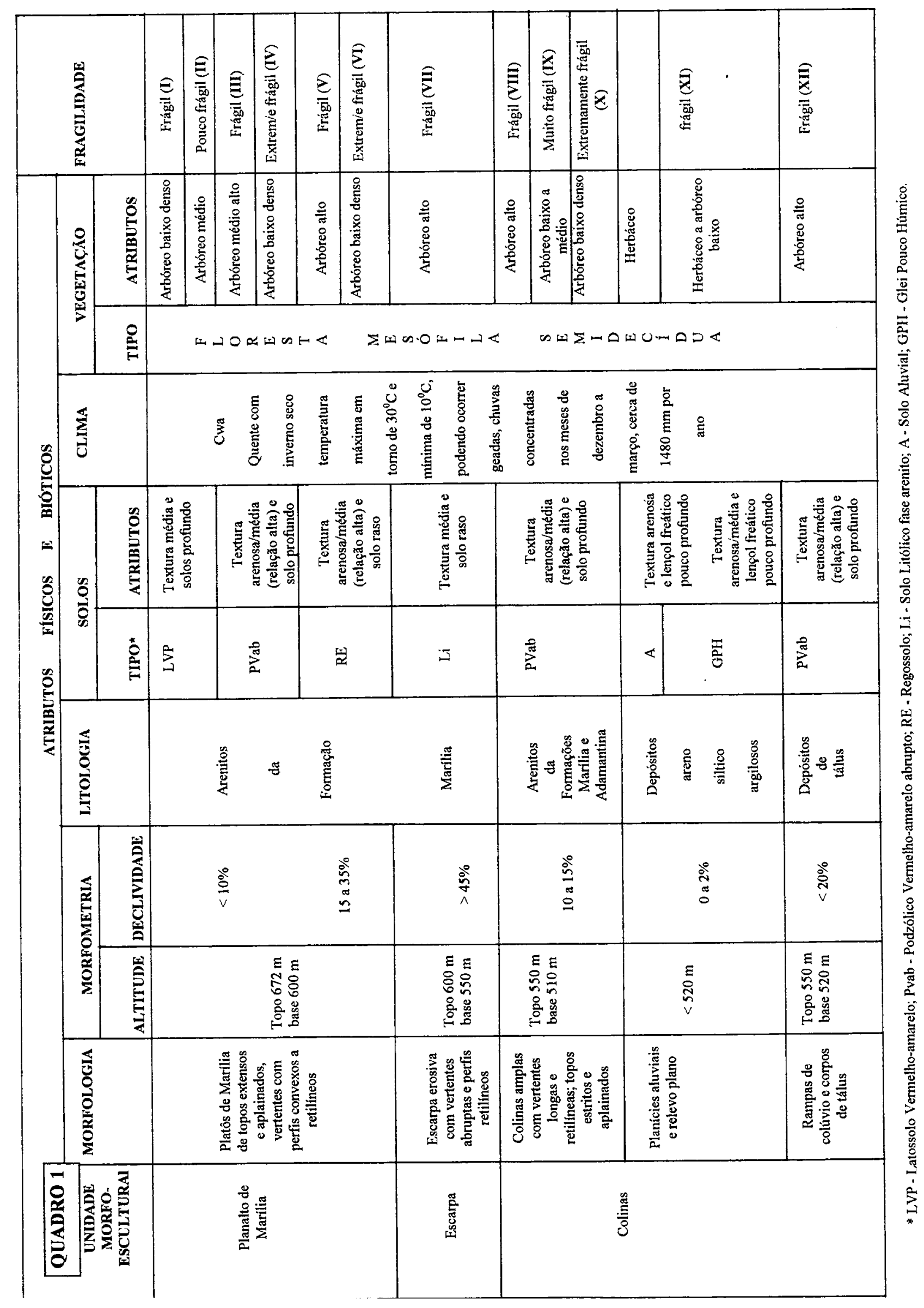




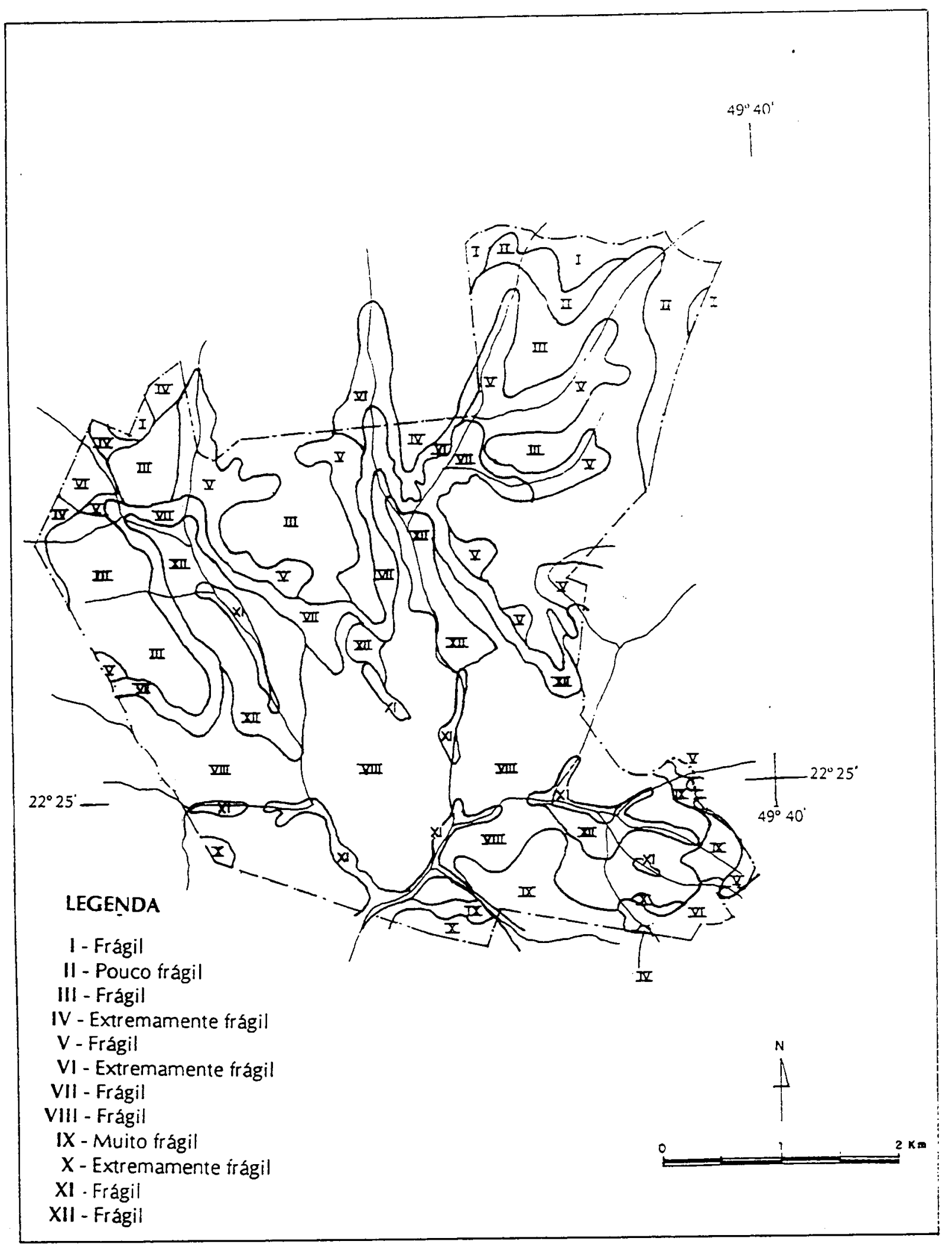

Figura 2: Mapa da fragilidade da Estação Ecológica dos Caetetus. 